\title{
Multilayers for Eefficient Thermal Energy Conversion in High Vacuum Flat Solar Thermal Panels
}

\author{
Davide De Maio ${ }^{\mathrm{a}, \mathrm{b}}$, Carmine D’Alessandro ${ }^{\mathrm{b}, \mathrm{a}}$, Antonio Caldarelli ${ }^{\mathrm{b}, \mathrm{a}}$, Daniela De Luca $^{\mathrm{c}, \mathrm{a}}$, Emiliano Di Gennaro $^{\mathrm{c}}$, \\ Maurizio Casalino $^{\mathrm{a}}$, Mario Iodice ${ }^{\mathrm{a}}$, Mariano Gioffrè ${ }^{\mathrm{a}}$, Roberto Russo ${ }^{\mathrm{a}}{ }^{*}$, Marilena Musto ${ }^{\mathrm{b}}$ \\ ${ }^{a}$ Consiglio Nazionale delle Ricerche, Istituto di Scienze Applicate e Sistemi Intelligenti, 80131 Napoli, Italy \\ ${ }^{b}$ Industrial Engineering Department, Università degli Studi di Napoli "Federico II", 80125 Napoli, Italy. \\ ${ }^{c}$ Physics Department, Universitàdegli Studi di Napoli "Federico II", 80125 Napoli, Italy.
}

\begin{abstract}
Multilayer absorbers based on $\mathrm{Cr}_{2} \mathrm{O}_{3}$ and $\mathrm{Cr}$, designed to improve the Solar-to-thermal conversion efficiency at mid temperatures in high vacuum flat thermal panel, are fabricated via sputtering deposition on bulk copper substrates and characterized by thermal and optical analysis. The refractive index of the single layers has been measured and used to estimate absorber thermal efficiency at the operating temperatures. Multilayers have been produced via sputtering deposition on bulk copper substrates. The absorber multilayers can be $10 \%$ more efficient than the commercial alternative at $250{ }^{\circ} \mathrm{C}$ operating temperatures, reaching $380{ }^{\circ} \mathrm{C}$ stagnation temperature without Sun concentration. The thermal stability has been checked at temperature of $400{ }^{\circ} \mathrm{C}$ in vacuum for four hours. High vacuum flat thermal collectors, equipped with the produced selective solar absorbers can obtain unprecedented performances and can give important contribution to the energy transition from fossil fuels to renewable energy for efficient heat production.
\end{abstract}

Keywords: Selective Solar Absorber, refractive index, high vacuum flat panels, thermal conversion efficiency, radiative properties

\section{Introduction}

The energy transition from fossil fuels to renewable energy is an important goal of our society and Solar energy can play a key role in such transition [1]. Almost one third of the energy resources in the developed countries is nowadays used for heating and cooling [2], [3], and a large fraction of this energy can be provided by highly efficient solar thermal collectors. The most efficient solar thermal collector in the low temperature range is the High Vacuum solar thermal Flat Panel (HVFP) [4] produced by TVPSolar SA [5]. The Selective Solar Absorber (SSA) is the key component in determining the efficiency in HVFP. In particular, its thermal emittance determines the radiation losses, that represent the main loss source thanks to the presence of high vacuum. As explained by Cao [6] at temperature higher than $100{ }^{\circ} \mathrm{C}$ without concentration, the thermal emittance gains importance over the thermal absorption. However, all absorbers available in commerce [7], [8] and most of the absorbers present in literature [9], [10] have been developed to work for concentrated solar applications [11].

As pointed out by Moss and coworkers [12], HVFPs can be the most efficient collectors also at temperature up to $250{ }^{\circ} \mathrm{C}$ if they were equipped with an optimized SSA with thermal emittance of 0.04 . Unfortunately, commercially available absorbers have such low emittance value only at room temperature. Their emittance increases to 0.1 or more at temperatures higher than $200{ }^{\circ} \mathrm{C}$ resulting in an increase of radiative power losses,

\footnotetext{
*Roberto.Russo@na.isasi.cnr.it
} 
with a consequent decrease in efficiency. Very few scientific studies have been performed on SSAs for unconcentrated applications. The only SSAs developed to work in unconcentrated environment and temperature higher than $100{ }^{\circ} \mathrm{C}$, are reported in [13], [14]. The SSA based on semiconductor multilayer developed in [13] only reaches $220{ }^{\circ} \mathrm{C}$ as maximum temperature and authors claim that it could optimized to reach $300{ }^{\circ} \mathrm{C}$ maximum temperature. A SSA based on metal/dielectric multilayer, reported in [14], was deposited by e-beam on a glass/metal substrate. The glass substrate was chosen to perform ellipsometric characterization avoiding the roughness contribution to the optical response. Results were very promising: a very selective emissivity curve was obtained opening the route to high efficiencies in the temperature range (150-300) ${ }^{\circ} \mathrm{C}$ without concentration. However, the produced samples could not be measured in operating conditions [14] and preliminary results on copper bulk substrates indicated that the temperature stability is not adequate to mid temperature applications.

Nowadays, a commercially available SSA (Mirotherm from Alanod) is mounted in HVFPs, providing very good efficiency up to $150{ }^{\circ} \mathrm{C}$ operating temperatures. In the present study we present SSAs based on metal (Cr) and dielectric $\left(\mathrm{Cr}_{2} \mathrm{O}_{3}\right)$ multilayer deposited on $\mathrm{Cu}$ industrial substrate via DC magnetron sputtering, designed to work at temperatures higher than $150{ }^{\circ} \mathrm{C}$. They have been characterized in operating conditions by absorptance and thermal emittance measurements. SSA thermal stability was also verified at $400{ }^{\circ} \mathrm{C}$ under vacuum for 4 hours.

\section{Experimental and Theoretical Details}

The most important properties of a SSA are the spectrally averaged absorptivity $\bar{\alpha}$ (also referred to as solar absorptance) and the spectrally averaged emissivity $\bar{\varepsilon}(T)$ (also referred to as thermal emittance). They are defined and calculated according to the following equations:

$$
\begin{aligned}
& \bar{\alpha}=\frac{\int_{0.3 \mu m}^{2.5 \mu m} \alpha(\lambda) s(\lambda) d \lambda}{\int_{0.3 \mu m}^{2.5 \mu m} S(\lambda) d \lambda} \\
& \bar{\varepsilon}(T)=\frac{\int_{0}^{\infty} \varepsilon(\lambda) E_{b b}(\lambda, T) d \lambda}{\int_{0}^{\infty} E_{b b}(\lambda, T) d \lambda}
\end{aligned}
$$

where $\mathrm{S}(\lambda)\left(\mathrm{Wm}^{-2} \mu \mathrm{m}^{-1}\right)$ is the solar radiation spectrum and $\mathrm{E}_{\mathrm{bb}}(\lambda, \mathrm{T})\left(\mathrm{Wm}^{-2} \mu \mathrm{m}^{-1}\right)$ is the blackbody radiation spectrum depending on the radiation wavelength $\lambda$ and temperature $T$, with the wavelength $\lambda$ expressed in $\mu \mathrm{m}$. According to the energy conservation and the Kirchkoff's law of thermal radiation we have (for opaque materials with transmissivity $\tau(\lambda)=0$ ):

$$
\alpha(\lambda)=\varepsilon(\lambda)=1-\rho(\lambda)
$$

where $\rho(\lambda)$ is the wavelength dependent reflectivity.

The measurement of reflectivity allows to determine the spectral emissivity $\varepsilon(\lambda)$ and absorptivity $\alpha(\lambda)$ and, using eq.(1) and (2), their spectrally averaged quantities $\bar{\alpha}$ and $\bar{\varepsilon}(T)$ which in turn determine the coating efficiency $\eta_{\text {coat }}[11]$ :

$$
\eta_{\text {coat }}=\frac{q_{h}}{H_{a b s}}=\bar{\alpha}_{S}-\frac{\bar{\varepsilon}\left(T_{a}\right) \sigma\left(T_{a}^{4}-T_{a m b}^{4}\right)}{C H_{a b s}}
$$

where $H_{a b s}$ is the heat flux to the thermal system $\left(\mathrm{Wm}^{-2}\right), \sigma$ the Stefan-Boltzmann constant $\left(\mathrm{Wm}^{-2} \mathrm{~K}^{-4}\right)$, $T_{a}$ the absorber temperature $(\mathrm{K}), T_{a m b}$ the ambient temperature $(\mathrm{K})$ and $\mathrm{C}$ the concentration factor. 
According to the previous equations, the ideal spectral emissivity $\varepsilon(\lambda)$ that maximizes the coating efficiency is represented by a step function as the black line in figure 1a) having a value equal to 1 From UV region up to $2.5 \mu \mathrm{m}$ to maximize absorptance of the Sun radiation (orange area in figure 1a), and equal to 0 above $2.5 \mu \mathrm{m}$ to minimize the absorber blackbody emission (blue area in figure 1a). The wavelength at which the emissivity switches from 1 to 0 is the so-called cut-off wavelength $\left(\lambda_{\text {cut-off }}\right)$. However, such ideal behavior cannot be achieved experimentally and real SSAs typically have an emissivity curve similar to the red curve reported in figure $1 \mathrm{a}$.

It is clear from eq. (4) that, in absence of concentration (concentration factor $\mathrm{C}=1$ ), the coating efficiency $\eta_{\text {coat }}$ has a strong temperature dependence due to the Stephan Boltzmann emission term that can be mitigated by a very low value of the thermal emittance. The presence of concentration $\mathrm{C}>1$ reduces the radiation loss term and the emittance loses importance with respect to the solar absorptance term.

Since the blackbody irradiance is temperature dependent, also the ideal $\lambda_{\text {cut-off }}$, that maximizes the coating efficiency, depends on the absorber operating temperature and as well as on the concentration factor, as illustrated in figure 1b).
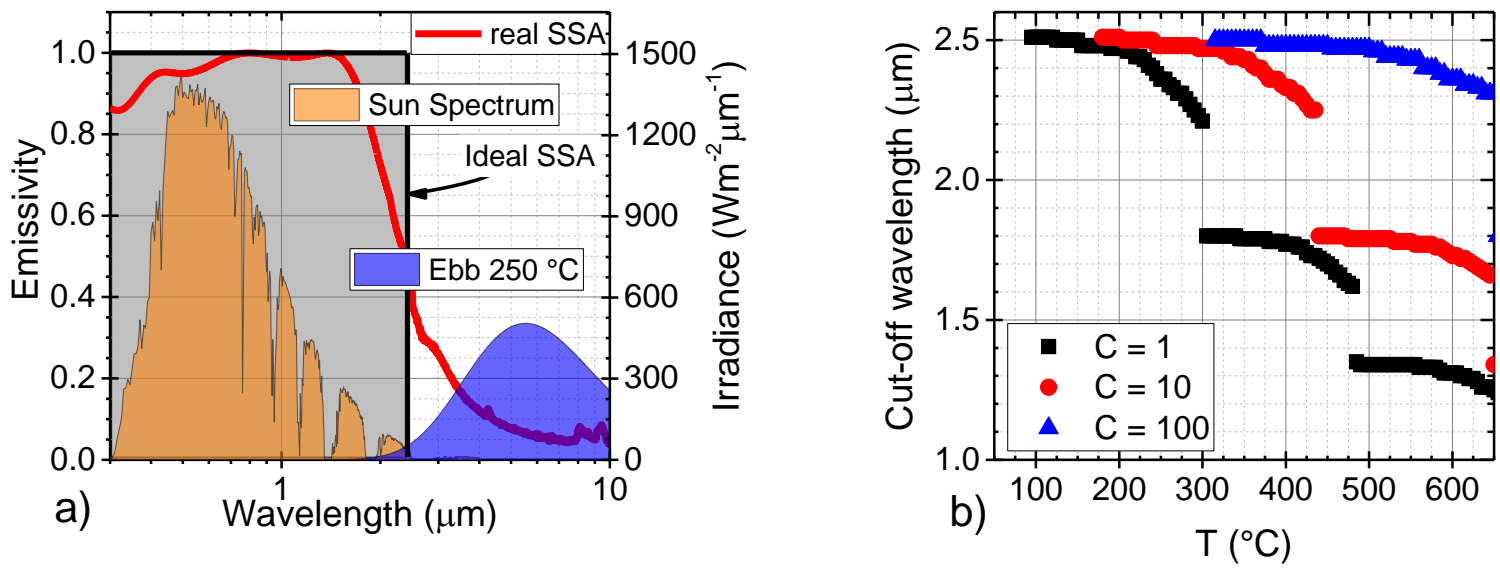

Figure 1 a) On the left axis spectral emissivity curve of real SSA (red line) and of an ideal SSA (black line). On the right axis the spectral irradiance of the Sun (orange area) and of a blackbody at a temperature of $250{ }^{\circ} \mathrm{C}$ (blue area). b) Ideal cut-off wavelength as function of the absorber temperature for different concentration factors.

In the present study we have fabricated multilayers with different $\lambda_{\text {cut-off }}$ to obtain the maximum efficiency at operating temperature higher than $150^{\circ} \mathrm{C}$. The spectral emissivity curve of the multilayer can be precisely calculated by transfer matrix method [15], if the dispersion laws of all materials are known. The dispersion law of the single layers was determined by ellipsometric measurements.

\subsection{Thin film deposition}

To deposit thin films and multilayers, a magnetron sputtering machine has been used. The system has a cylindrical vacuum chamber equipped with four sputtering targets of $10 \mathrm{~cm}$ diameter placed at 90 degrees from each other. A rotating supporting disc with four sample holders allows to place the substrates under the desired cathode and deposit up to four different materials without breaking the vacuum. The distance between the cathodes and the substrate is set to $10 \mathrm{~cm}$. $\mathrm{Cr}$ and $\mathrm{Cr}_{2} \mathrm{O}_{3}$ thin films are deposited from a $99.99 \%$ pure $\mathrm{Cr}$ cathode by means of DC magnetron sputtering and DC reactive magnetron sputtering process respectively. Argon was used as a sputtering gas for $\mathrm{Cr}$ deposition and oxygen was added as a reactive gas for $\mathrm{Cr}_{2} \mathrm{O}_{3}$ deposition. Flow rates are controlled by means of flowmeters and mass flow controllers. Pressure in the chamber, during the sputtering process, is measured by a capacitance gauge (Pfeiffer CMR 364). For Cr deposition, argon flow was set at $3.3 \mathrm{sccm}$ corresponding to a pressure of $0.2 \mathrm{~Pa}$. During $\mathrm{Cr}_{2} \mathrm{O}_{3}$ deposition an oxygen flow of $1.6 \mathrm{sccm}$ was 
chosen to obtain stable deposition condition that produces $\mathrm{Cr}_{2} \mathrm{O}_{3}$ films with the required dielectric properties [16]. All samples are loaded in the chamber the day before and pumped down overnight by a $1500 \mathrm{l} / \mathrm{s}$ turbomolecular pump to obtain the same base pressure of about $2 \times 10^{-5} \mathrm{~Pa}$. Before gas injection, the turbo pumping speed is reduced by a throttle valve without affecting the base pressure. A rotating shutter placed at few $\mathrm{cm}$ from the cathodes is used to control the deposition time and, as consequence the layer thickness.

Fig 2 reports the discharge voltage As function of the oxygen flow rate, having set the argon flow rate at 3.3 $\mathrm{sccm}$ and the discharge current at $0.5 \mathrm{~A}$. It can be noted that, increasing the oxygen flow rate from zero, the total pressure (right-y axis) is unchanged up to a flow rate of $3 \mathrm{sccm}$ and also discharge voltage is almost constant, indicating that all injected oxygen is absorbed by the $\mathrm{Cr}$ film and $\mathrm{Cr}$ target and the target remains metallic.

At $3 \mathrm{sccm}$ the discharge voltage starts to increase due to cathode poisoning [16], also total pressure has a jump and for increasing oxygen flows the pressure starts to increase linearly with the oxygen flow indicating that the nitrogen pumping speed of $\mathrm{Cr}$ target and of the growing film is no more effective [17].

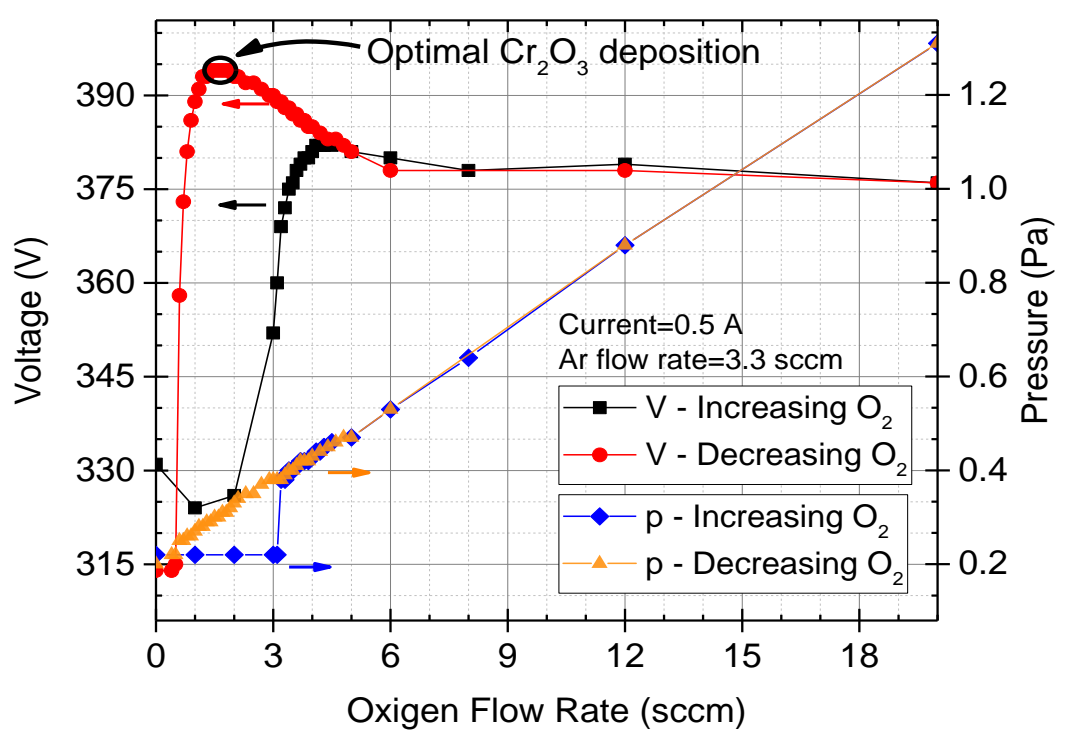

Figure 2 Left axis: voltage discharge for a fixed DC sputtering current $(0.5 \mathrm{~A})$ and fixed Argon flow rate $(3.3 \mathrm{sccm})$ as function of the oxygen flow rate (black square increasing flow rate, red dots decreasing flow rate). Right axis: total pressure as function of the oxygen flow rate

According to [16], we fully oxidized the cathode at higher oxygen flow rate $(20 \mathrm{sccm})$ and operated the deposition in the decreasing $\mathrm{O}_{2}$ flow region, where the discharge voltage presents a maximum. Such optimal flow rate, corresponding to the maximum discharge voltage, represents the stable condition that guarantees less oxygen impurities in the growing film and it is indicated by the circle in figure 2 . For oxygen flow rates lower than the maximum, the cathode starts to fall back in the metallic condition, whereas at higher oxygen flow rate there is an excess of oxygen in the plasma that can be included in the growing film. It is worth to note that decreasing the oxygen flow rate from a fully oxidized cathode produces a linear decrease in total pressure down to the zero-oxygen flow rate that recovers the target to the original metallic condition. Before starting the deposition on substrates, the cathode is exposed to the discharge for $15 \mathrm{~min}$ to condition it and to obtain stable and reproducible depositions.

The multilayer $\mathrm{Cr}_{2} \mathrm{O}_{3} / \mathrm{Cr} / \mathrm{Cr}_{2} \mathrm{O}_{3}$ is completed with $\mathrm{SiO}_{2}$ thin film used as AntiReflecting (AR) coating and deposited by RF magnetron sputtering technique in pure argon atmosphere. The deposition conditions, for the various layers, are reported in table 1. The copper substrate is also reported in the table to complete the SSA structure. 


\begin{tabular}{|c|c|c|c|c|c|c|c|c|}
\hline layer & $\begin{array}{c}\text { Air flow } \\
(\mathrm{sccm})\end{array}$ & $\begin{array}{c}\mathrm{O}_{2} \text { flow } \\
(\mathrm{sccm})\end{array}$ & $\begin{array}{c}\text { Discharge } \\
\text { Current } \\
(\mathrm{A})\end{array}$ & $\begin{array}{c}\text { Discharge } \\
\text { Voltage } \\
(\mathrm{V})\end{array}$ & $\begin{array}{c}\text { Rate } \\
(\mathrm{nm} / \mathrm{s})\end{array}$ & $\begin{array}{c}\text { Pressure } \\
(\mathrm{Pa})\end{array}$ & $\begin{array}{c}\text { Time1 } \\
(\mathrm{s})\end{array}$ & $\begin{array}{c}\text { Time2 } \\
(\mathrm{s})\end{array}$ \\
\hline $\mathrm{SiO}_{2}$ & 4.0 & 0.0 & $200 \mathrm{~W}$ & $(\mathrm{RF})$ & 0.11 & 0.3 & 673 & 607 \\
\hline $\mathrm{Cr}_{2} \mathrm{O}_{3}$ & 3.3 & 1.6 & $0.5 \mathrm{~A}$ & $395 \mathrm{~V}$ & 0.14 & 0.3 & 386 & 321 \\
\hline $\mathrm{Cr}$ & 3.3 & 0.0 & $0.3 \mathrm{~A}$ & $300 \mathrm{~V}$ & 0.44 & 0.2 & 21 & 18 \\
\hline $\mathrm{Cr}_{2} \mathrm{O}_{3}$ & 3.3 & 1.6 & $0.5 \mathrm{~A}$ & $395 \mathrm{~V}$ & 0.14 & 0.3 & 193 & 100 \\
\hline \multicolumn{7}{|l|}{ Copper substrate }
\end{tabular}

Tab.1 Parameters for deposition of the different layers on copper substrate: the two multilayers differ for the deposition time reported in the last two columns: time1 (time2) refers to coating designed to work at $200^{\circ} \mathrm{C}\left(300^{\circ} \mathrm{C}\right)$.

The reported deposition rates are calculated by the ratio between the layer thickness measured with a profilometer (KLA Tencor P-15) and the deposition time. The step height to calibrate the deposition rates are typically about $300 \mathrm{~nm}$ and they are obtained in dedicated layers by lift-off procedure in acetone, using standard photolithographic techniques. Single layers were deposited on optically flat substrates to determine the optical properties by ellipsometric measurements, whereas multilayers were deposited on bulk copper from KME and measured in the calorimetric system up to the stagnation temperature.

\subsection{Optical Layer characterization}

To evaluate the refractive indices of the material constituing the multilayer absorber we used the ellipsometric technique. Measures were carried out by means of a phase modulated spectroscopic ellipsometer (Horiba Jobin Yvon UVISEL) in the wavelength range 300-1600 nm at an incidence angle of $70^{\circ}$. Measures were performed on layers deposited in the same conditions reported in section 2.1, on a different substrate, consisting of an aluminum film grown on a glass support to be optically flat substrate. Thickness and complex refractive index $\tilde{\mathrm{n}}(\lambda)$ of the film were obtained by fitting the experimental data with numerical data returned by an optical model of the sample in which material dispersions are described by analytical formula. The experimental data were fitted by using the Forouhi-Bloomer formula for the chromium oxide [18] [19], while for chromium Drude-Lorentz [20] dispersion relation has been used.

Figures $3 \mathrm{a}$ ) and $3 \mathrm{~b}$ ) show the refractive index dispersion for both chromium and chromium oxide which best fit the ellipsometric experimental data, used for the optical simulations. The reported refractive indices were able to fit $\mathrm{Cr}_{2} \mathrm{O}_{3}$ film for thicknesses from $15 \mathrm{~nm}$ up to $100 \mathrm{~nm}$ and $\mathrm{Cr}$ layer from 5 to $30 \mathrm{~nm}$ and they were obtained by fitting experimental data of several samples. The use of optically smooth surfaces allowed to exclude surface roughness effects in the models.

Since the ellipsometric analysis is limited in the range between $300 \mathrm{~nm}$ and $1600 \mathrm{~nm}$, refractive indices of both chromium and chromium oxide have been extended outside the measured wavelength range by using the respective dispersion relations. The results show good agreement with literature data [21]-[23]. Reflection measurements further confirm the effectiveness of the obtained refractive indices: figure $3 \mathrm{c}$ ) shows a comparison between measured and simulated reflection of a $\mathrm{Cr}_{2} \mathrm{O}_{3} / \mathrm{Cr}$ bilayer on aluminium substrate (model and layer thickness in inset). Integrating sphere coupled with an Optical Spectrum Analyzer was used to measure VIS-NIR range $(0.35-1.75 \mu \mathrm{m})$ reflectance and Fourier Transform Infrared Spectroscopy (FTIR) was used to measure reflectance in range 1.00-4.00 $\mu \mathrm{m}$. The two instruments overlap in the range 1.00-1.75 $\mu \mathrm{m}$ indicating a good agreement between the two different measurement techniques. The optical simulation of the sample under investigation uses the refractive indices reported in figure 3 and literature data for $\mathrm{Al}_{2} \mathrm{O}_{3}$ and Al substrate [20], [21], [24]. The agreement between optical simulation and the reflectance measurements validates the studied refractive index for both chromium and chromium oxide in the whole wavelength range. 

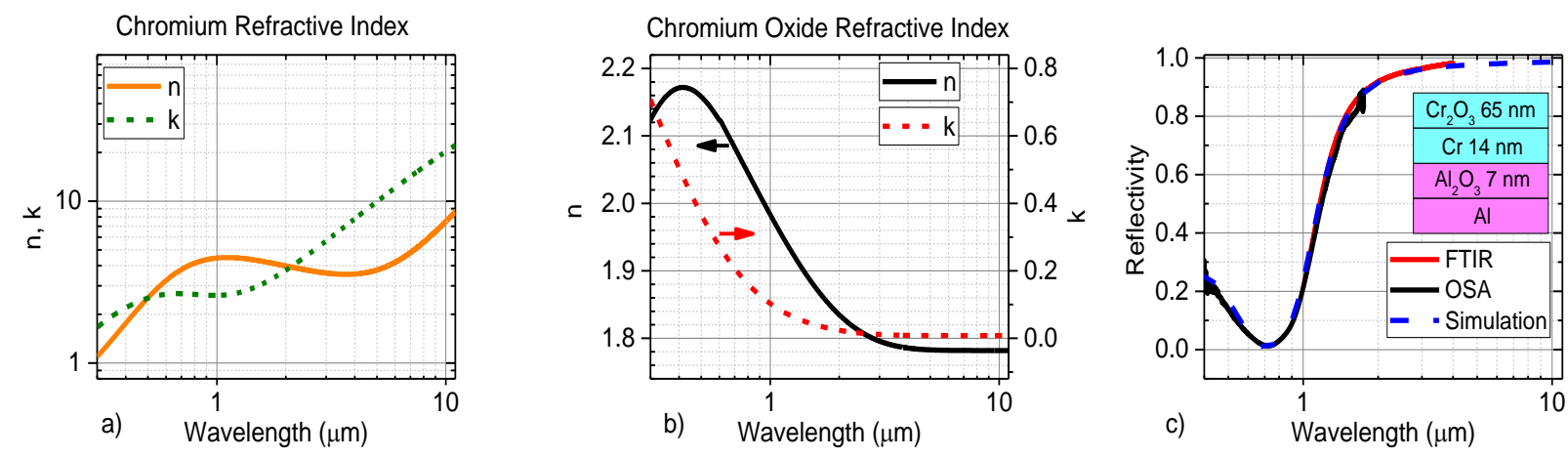

Figure 3 Refractive index and extinction coefficient obtained by fitting ellipsometric measurements for Chromium (a) and Chromium Oxide (b) . c) the agreement between experimental data and simulation obtained using the reported refractive indices is shown.

\subsection{Multilayer simulation and characterization}

The refractive index obtained by the ellipsometric data were used to design the SSA for operating temperature of $200{ }^{\circ} \mathrm{C}$ and $300{ }^{\circ} \mathrm{C}$ according to procedure reported in [14] and resulted in the deposition time reported in table 1 .

Optical properties of multilayers deposited on bulk copper were measured at room temperature by hemispherical spectral reflectivity measurement in the range (400-1700) $\mathrm{nm}$ using an integrating sphere connected to an optical spectrum analyzer and by absorptance and emittance measurement in operating condition under vacuum using a calorimetric method [14].

\section{Results and Discussions}

Using the refractive indices reported in the section 2.2 , it is possible to predict the reflectivity of multilayer as function of the layer thicknesses. Then, using eq. 3,1 and 2 is possible to calculate the spectrally average emissivity and absorptivity. In Figure 4 a) we report the result for two coatings designed to work at Operating Temperatures (OT) higher than $150{ }^{\circ} \mathrm{C}$ (coating 1 at $\mathrm{OT}=200{ }^{\circ} \mathrm{C}$ and coating $2 \mathrm{OT}=300{ }^{\circ} \mathrm{C}$ ). The reported thermal emittance is extremely low. To obtain such low values of emittance the cut-off wavelength has to move at wavelength shorter than the one of the commercial absorber; as consequence the solar absorptance is slightly reduced. The calculated absorptance values, according to equation 1, are 0.95 for coating working at $200{ }^{\circ} \mathrm{C}$ and 0.89 for coating working at $300{ }^{\circ} \mathrm{C}$.
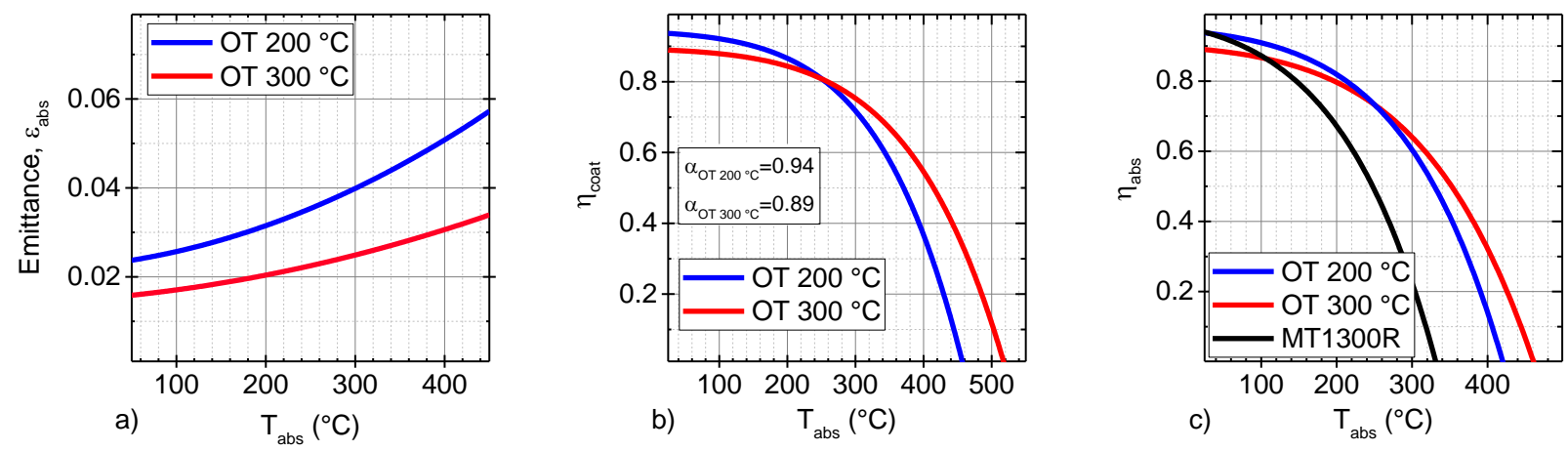

Figure 4 a) Thermal emittance vs temperature for the two coating designed to work at $200{ }^{\circ} \mathrm{C}$ (blue line) and $300{ }^{\circ} \mathrm{C}$ (red line). $b$ ) Efficiency of the coatings $\left(O T=200^{\circ} \mathrm{C}\right.$ blue line and $O T=300^{\circ} \mathrm{C} \mathrm{red} \mathrm{line).} c$ ) Efficiency calculated according to eq. 5 for the same coatings of figure $b$ ) compared with the commercial coating (MT1300R black line). 
The coating efficiency, calculated according to eq. (4), is reported in figure $4 \mathrm{~b}$ as function of temperature. Calculation assume an illuminating power density of $1000 \mathrm{~W} / \mathrm{m}^{2}$ and an ambient temperature equal to $20{ }^{\circ} \mathrm{C}$. However, the absorber efficiency $\eta_{a b s}$ has to take in to account also the thermal emittance of the substrate $\bar{\varepsilon}_{s}$ that can be considered temperature independent. The absorber efficiency can be expressed by eq (5)

$$
\eta_{a b s}=\frac{q_{h}}{H_{a b s}}=\bar{\alpha}_{S}-\frac{\bar{\varepsilon}\left(T_{a}\right) \sigma\left(T_{a}^{4}-T_{a m b}^{4}\right)}{C H_{a b s}}-\frac{\bar{\varepsilon}_{s} \sigma\left(T_{a}^{4}-T_{a m b}^{4}\right)}{C H_{a b s}}
$$

and assuming a copper emissivity of 0.02 , the expected $\eta_{a b s}$ is reported in figure 4c) for the two multilayers and for the Mirotherm (absorptance 0.95, coating thermal emittance $\bar{\varepsilon}\left(T_{a}\right)=0.06+3.4 *$ $10^{-5} T+2.66 * 10^{-7} T^{2}$, aluminium substrate emittance $\bar{\varepsilon}_{s}=0.03$, illuminating power density $1000 \mathrm{~W} / \mathrm{m}^{2}$ )[25].

The simulated multilayers have been deposited as described in section 2.1 on a copper bulk substrate 0.2 $\mathrm{mm}$ thick. A metallic frame was used to avoid deposition on the back side of copper substrate. To correctly measure the SSA optical properties in the emissometer, the spurious contributions to absorber temperature (such as the thermal conductance and capacitance of thermocouple, support etc.) should be negligible. Therefore, the sample dimensions have been chosen to be $10 \mathrm{~cm} x 10 \mathrm{~cm}$, comparable to the sputtering target diameter. The picture of multilayers after deposition can be observed in figure 5 a). To check thickness uniformity, we have performed the spectral absorptivity measurements in the center of the sample as well as along the diagonals and the midlines, as reported in figure 5b). Despite the large area reflectivity is very low and uniform over all the absorber surface for wavelengths below $1 \mu \mathrm{m}$. At wavelength large than $1 \mu \mathrm{m}$, the results in figure $5 \mathrm{~b}$ indicate that the absorptivity follows the sample symmetry respect to the center: the reflectivity curve measured on the midlines (red curves) are very similar among them, and they are in between the center (thick dark red curve) and the diagonal point (light orange curves). The reflectivity curve measured in the sample center presents the lowest reflectivity curve it is in agreement with the simulation (black dashed curve). This result is not surprising since the deposition rate was calculated on the sample center and as consequence only in the center the correct layer thickness is guaranteed and the maximum absorptance is obtained. In figure $5 \mathrm{~b}$ ) the averaged absorptivity obtained from the average of the 9 measurements is also reported as black thick curve. The averaged absorptivity will be used to compare the results of the thermal stability test.

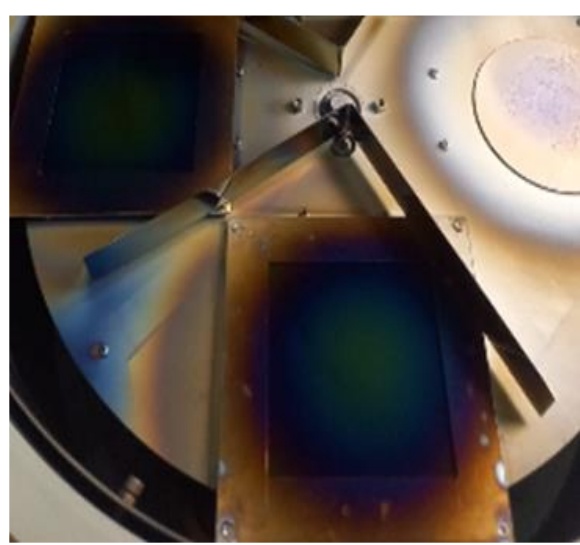

a)

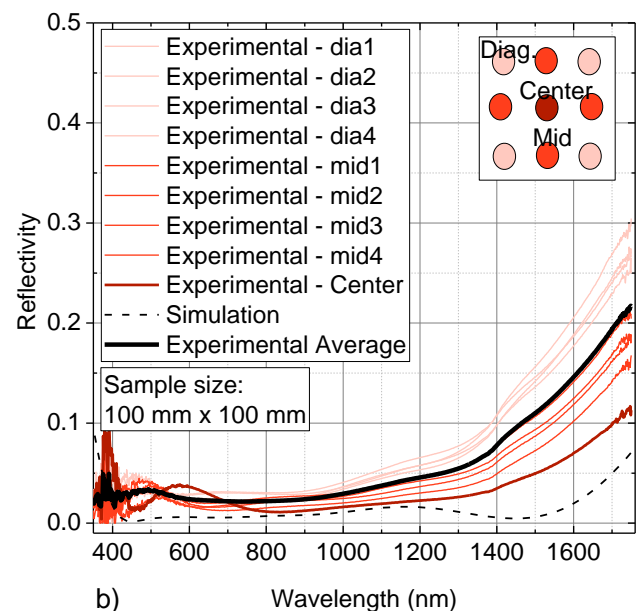

b)

Figure 5 a) Photo of the SSA just after the deposition, b) SSA reflectivity measurement on 9 points arranged as illustrated in the inset and their average (black thick curve). Also reported is the expected reflectivity (black dashed line) 
The samples were mounted in a custom emissometer [14], [25] to measure absorptance and emittance in operating conditions. During the measurement the vacuum enclosure, that surrounds the absorber and keeps it under vacuum, reaches a stable and uniform temperature of about $50{ }^{\circ} \mathrm{C}$. The measurement allows to estimate the overall absorber emittance $\bar{\varepsilon}_{a b s}=\bar{\varepsilon}\left(T_{a}\right)+\bar{\varepsilon}_{s}$ and to extrapolate the coating emittance $\bar{\varepsilon}\left(T_{a}\right)$ if $\bar{\varepsilon}_{S}$ is known.

Results for the two samples are reported in figure 6 a) and compared with commercial absorber (black line). The absorber emittance is higher than expected from simulation of about 0.04 for both multilayers. The slight discrepancy in absorber emittance can have different origins and need more investigations. However, despite an emittance higher than expected the absorber efficiency is better than commercial absorber at temperatures higher than $150{ }^{\circ} \mathrm{C}$, as illustrated in figure $6 \mathrm{~b}$. In particular, the absorber efficiency at $250{ }^{\circ} \mathrm{C}$, calculated according to the experimental values (see figure 6a), increases from 0.490 for Mirotherm up to 0.593 for coating designed to work at $300{ }^{\circ} \mathrm{C}$, with a $10 \%$ absolute efficiency improvement $(21 \%$ relative increase). At $300{ }^{\circ} \mathrm{C}$ the efficiency improvement is even more pronounced: the sample designed for such temperature has $\eta_{a b s}=0.425$ compared with $\eta_{a b s}=0.225$ of the Mirotherm at the same temperature, with a $20 \%$ absolute improvement corresponding to about $90 \%$ relative increase. As consequence of the low emittance, the stagnation temperature, that is the temperature at which the incident power is equal to the emitted power and efficiency is equal to zero, increases from 331 up to $380^{\circ} \mathrm{C}$.
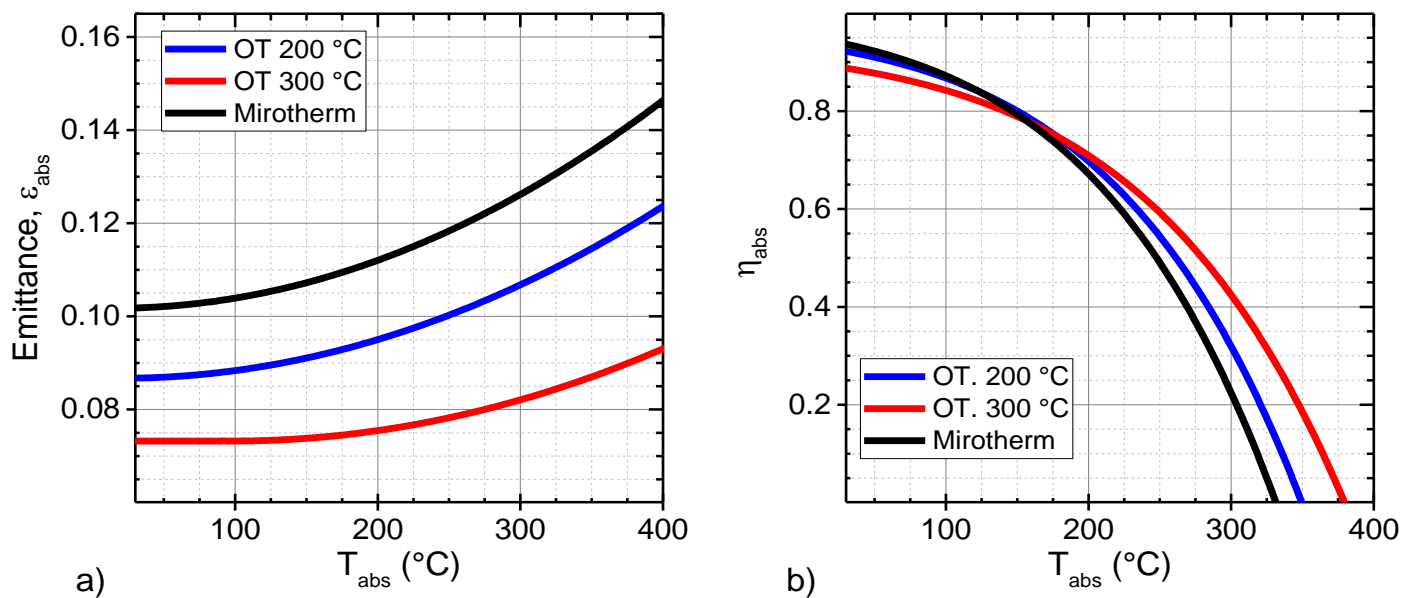

Figure 6 a) Absorber emittance measured at temperature up to $400{ }^{\circ} \mathrm{C}$ for commercial coating (Mirotherm black line), SSA designed to work at $200^{\circ} \mathrm{C}$ (blue line) and $300^{\circ} \mathrm{C}$ (red line). b) Absorber efficiency calculated according to equation (5) for Mirotherm (Black line) and multilayer coating designed to work at $200{ }^{\circ} \mathrm{C}$ (blue line) and $300{ }^{\circ} \mathrm{C}$ (red line).

It is worth to mention that the reported results are the average on a relatively large area substrate $(10 \mathrm{~cm}$ $\mathrm{x} 10 \mathrm{~cm}$ ), having a slightly non uniformity. Using larger deposition system, with industrial sputtering cathode it would improve uniformity and performances.

To test the thermal stability of the realized absorbers, they have been kept at $400{ }^{\circ} \mathrm{C}$ for four hours under high vacuum. After the thermal cycle, absorptance and emittance were measured again at operating temperature and the difference in the results were within the experimental error. Also, the spectral reflectivity measurements before and after the thermal stability test are very similar as can be noticed in figures 7 a) and $7 \mathrm{~b}$ ). For clarity we have reported only the average reflectivity curve, obtained as in figure $5 \mathrm{~b}$ ), before and after the thermal stability test. There is some small change in the absorptivity curve, however the slight decrease in reflectivity in the region around 500-600 nm, where the Sun spectrum has the maximum intensity, compensates the slight increase in reflectivity at wavelength above $1000 \mathrm{~nm}$ and the absorptance value is unchanged. 

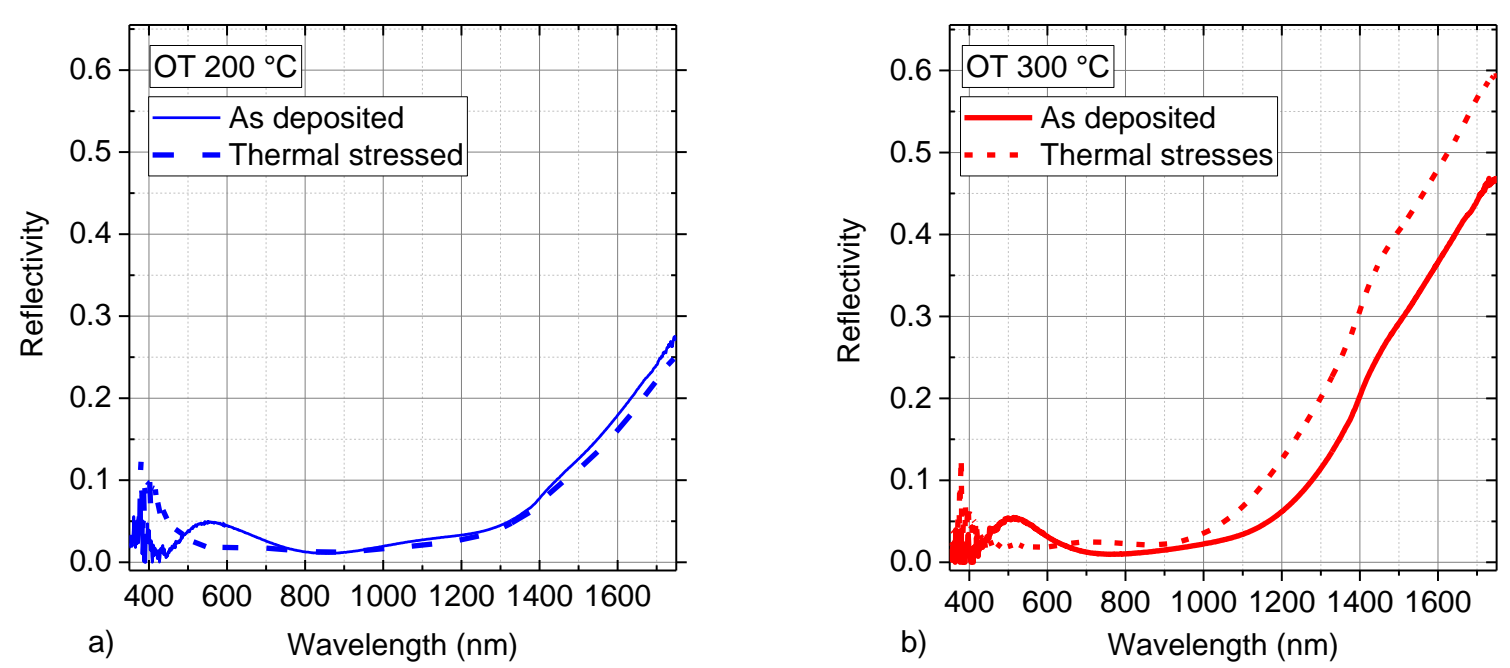

Figure 7 reflectivity measurement before and after the thermal stability test for a) SSA designed to work at $200^{\circ} \mathrm{C}$ ) and b) SSA designed to work at $300^{\circ} \mathrm{C}$

Preliminary results on the ageing of coatings designed to work at $300^{\circ} \mathrm{C}$ indicate that the service lifetime will be larger than 25 years [26].

\section{Conclusions}

The use of Cr based multilayers to realize selective solar absorbers open the route to the application of high vacuum flat panels as very efficient thermal solar collectors at temperature up to $250-300^{\circ} \mathrm{C}$. The multilayers are realized via sputtering deposition techniques and their fabrication process can be easily transferred to industrial deposition systems.

The presented selective solar absorbers have a very low emittance preserving a large absorptance and reaching stagnation temperature in excess of $350^{\circ} \mathrm{C}$ with superior performances with respect to commercial coatings. Absorber efficiency higher than $70 \%$ at $200^{\circ} \mathrm{C}$ and higher than $40 \%$ at $300^{\circ} \mathrm{C}$ have been obtained. However, the measured thermal emittances on copper bulk substrates are slightly higher than expected by simulations. The origin of such increase can be the surface roughness and/or the presence of copper oxides at the interface between substrate and multilayer. Understanding the origin of the increased emittance would allow to further improve the SSA performances.

\section{Acknowledgments}

The Ph.D. grant of two of the authors (DDL, AC) is funded by the PON2014-2020 "Dottorati innovativi con caratterizzazione industriale, XXXIV ciclo" program. The Ph.D. grant of one of the authors (DDM) is funded by the CNR-Confindustria "Dottorati di Ricerca Industriali" program XXXIV ciclo.

\section{References}

[1] A. J. Chapman, B. C. McLellan, and T. Tezuka, 'Prioritizing mitigation efforts considering co-benefits, equity and energy justice: Fossil fuel to renewable energy transition pathways’, Applied Energy, vol. 219, pp. 187-198, Jun. 2018, doi: 10.1016/j.apenergy.2018.03.054.

[2] T. Fleiter et al., 'Profile of heating and cooling demand in 2015', 2017, [Online]. Available: https://heatroadmap.eu/wpcontent/uploads/2018/11/HRE4_D3.1.pdf. 
[3] Lukas Kranzl et al., 'Hotmaps 2030/2050 scenarios for the heating and cooling sectors', Hotmaps Project, May 31, 2018. https://www.hotmaps-project.eu/hotmaps-2030-2050-scenarios-for-the-heating-and-cooling-sectors/ (accessed Apr. 02, 2021).

[4] A. Buonomano et al., 'Experimental analysis and dynamic simulation of a novel high-temperature solar cooling system', Energy Conversion and Management, vol. 109, pp. 19-39, Feb. 2016, doi: 10.1016/j.enconman.2015.11.047.

[5] 'TVP Solar'. https://www.tvpsolar.com/ (accessed Jul. 23, 2020).

[6] F. Cao, K. McEnaney, G. Chen, and Z. Ren, 'A review of cermet-based spectrally selective solar absorbers', Energy Environ. Sci., vol. 7, no. 5, p. 1615, 2014, doi: 10.1039/c3ee43825b.

[7] 'Alanod', Home. https://alanod.com/ (accessed Jul. 23, 2020).

[8] 'ALMECO GROUP - Alluminio - ALMECO GROUP'. https://www.almecogroup.com/it (accessed Apr. 02, 2021).

[9] H. C. Barshilia, N. Selvakumar, K. S. Rajam, D. V. Sridhara Rao, and K. Muraleedharan, 'Deposition and characterization of TiAlN/TiAlON/Si3N4 tandem absorbers prepared using reactive direct current magnetron sputtering', Thin Solid Films, vol. 516, no. 18, pp. 6071-6078, Jul. 2008, doi: 10.1016/j.tsf.2007.10.113.

[10] T. K. Tsai, Y. H. Li, and J. S. Fang, 'Spectral properties and thermal stability of CrN/CrON/A12O3 spectrally selective coating', Thin Solid Films, vol. 615, pp. 91-96, Sep. 2016, doi: 10.1016/j.tsf.2016.06.055.

[11] K. Xu, M. Du, L. Hao, J. Mi, Q. Yu, and S. Li, 'A review of high-temperature selective absorbing coatings for solar thermal applications', Journal of Materiomics, vol. 6, no. 1, pp. 167-182, Mar. 2020, doi: 10.1016/j.jmat.2019.12.012.

[12] R. W. Moss, P. Henshall, F. Arya, G. S. F. Shire, T. Hyde, and P. C. Eames, 'Performance and operational effectiveness of evacuated flat plate solar collectors compared with conventional thermal, PVT and PV panels', Applied Energy, vol. 216, pp. 588-601, Apr. 2018, doi: 10.1016/j.apenergy.2018.01.001.

[13] N. H. Thomas, Z. Chen, S. Fan, and A. J. Minnich, 'Semiconductor-based Multilayer Selective Solar Absorber for Unconcentrated Solar Thermal Energy Conversion', Scientific Reports, vol. 7, no. 1, Art. no. 1, Jul. 2017, doi: 10.1038/s41598-017-05235-x.

[14] D. De Maio et al., 'A Selective Solar Absorber for Unconcentrated Solar Thermal Panels', Energies, vol. 14, no. 4, p. 900, Feb. 2021, doi: 10.3390/en14040900.

[15] A. Macleod, Thin Film Optical Filters, 4th ed. USA: CRC Press, 2010.

[16] G. Contoux, F. Cosset, A. Célérier, and J. Machet, 'Deposition process study of chromium oxide thin filmsobtained by d.c. magnetron sputtering', Thin Solid Films, vol. 292, no. 1-2, pp. 75-84, Jan. 1997, doi: 10.1016/S0040-6090(96)08941-9.

[17] K. Strijckmans, R. Schelfhout, and D. Depla, 'Tutorial: Hysteresis during the reactive magnetron sputtering process', Journal of Applied Physics, vol. 124, no. 24, p. 241101, Dec. 2018, doi: 10.1063/1.5042084.

[18] A. R. Forouhi and I. Bloomer, 'Optical dispersion relations for amorphous semiconductors and amorphous dielectrics', Phys. Rev. B, vol. 34, no. 10, pp. 7018-7026, Nov. 1986, doi: 10.1103/PhysRevB.34.7018.

[19] A. R. Forouhi and I. Bloomer, 'Optical properties of crystalline semiconductors and dielectrics', Phys. Rev. B, vol. 38, no. 3, pp. 1865-1874, Jul. 1988, doi: 10.1103/PhysRevB.38.1865.

[20] D. Barchiesi and T. Grosges, 'Fitting the optical constants of gold, silver, chromium, titanium, and aluminum in the visible bandwidth', JNP, vol. 8, no. 1, p. 083097, Jan. 2014, doi: 10.1117/1.JNP.8.083097.

[21] A. D. Rakić, A. B. Djurišić, J. M. Elazar, and M. L. Majewski, 'Optical properties of metallic films for vertical-cavity optoelectronic devices', Appl. Opt., AO, vol. 37, no. 22, pp. 5271-5283, Aug. 1998, doi: 10.1364/AO.37.005271.

[22] H. C. Barshilia, N. Selvakumar, K. S. Rajam, and A. Biswas, 'Structure and optical properties of pulsed sputter deposited $\mathrm{CrxOy} / \mathrm{Cr} / \mathrm{Cr} 2 \mathrm{O} 3$ solar selective coatings', Journal of Applied Physics, vol. 103, no. 2, p. 023507, Jan. 2008, doi: $10.1063 / 1.2831364$

[23] M. F. Al-Kuhaili and S. M. A. Durrani, 'Optical properties of chromium oxide thin films deposited by electron-beam evaporation', Optical Materials, vol. 29, no. 6, pp. 709-713, Feb. 2007, doi: 10.1016/j.optmat.2005.11.020.

[24] R. Boidin, T. Halenkovič, V. Nazabal, L. Beneš, and P. Němec, 'Pulsed laser deposited alumina thin films', Ceramics International, vol. 42, no. 1, Part B, pp. 1177-1182, 2016, doi: 10.1016/j.ceramint.2015.09.048.

[25] R. Russo, M. Monti, F. di Giamberardino, and V. G. Palmieri, 'Characterization of selective solar absorber under high vacuum', Opt. Express, vol. 26, no. 10, p. A480, May 2018, doi: 10.1364/OE.26.00A480.

[26] Antonio Caldarelli, Carmine D'alessandro, Davide De Maio, Daniela De Luca, Eliana Gaudino, Marilena Musto, Emiliano Di Gennaro and Roberto Russo, 'Characterization and Thermal Aging Tests of Cr Based Multilayer for Unconcentrated Solar Thermal Applications’ unpublished. 